\title{
TEORIA DA PAISAGEM EM CADERNOS DE BORDO: UMA EXPERIÊNCIA NO ENSINO DE ARQUITETURA E URBANISMO
}

\author{
LANDSCAPE THEORY INTO LOGBOOKS: \\ AN APPROACH IN ARCHITECTURE AND URBANISM LEARNING \\ Julieta Maria Vasconcelos Leite* \\ Rafaela Rodrigues Alves Souza**
}

\section{RESUMO}

Este texto apresenta os resultados de uma experiência pedagógica do curso de Arquitetura e Urbanismo da Universidade Federal de Pernambuco (UFPE) na disciplina de Tópicos Especiais em Teoria III. A disciplina visa introduzir ao aluno noções de teoria da paisagem. Parte-se da noção de que nós somos integrantes da paisagem e, por isso, seu entendimento fundamenta-se na percepção e na experiência, englobando aspectos subjetivos. A experiência pedagógica consolida-se no exercício do Caderno de Bordo, elaborado individualmente pelos alunos, onde as suas reflexões são apresentadas de maneira associada a fotografias ou desenhos de paisagens produzidas por eles. A análise dos Cadernos revela maior sensibilização dos alunos em relação à paisagem, despertando olhar crítico sobre o pensar e construir paisagens e fornecendo bases que auxiliam no desenvolvimento de seus projetos de arquitetura, urbanismo e paisagismo.

Palavras-chave: Ensino. Arquitetura e Urbanismo. Teoria da paisagem. Cadernos de bordo.

\section{ABSTRACT}

This text presents an educational experiment adopted with undergraduate students of Architecture and Urbanism at Universidade Federal de Pernambuco (UFPE). Our aim is to present to the students some landscape theory impressions. It is assumed that we are a whole part of the landscape and that our knowledge about it comes from how we perceive and experience it. The experiment is funded into logbooks individually elaborated by the students. Their thoughts were presented among the pictures or the drawings

\footnotetext{
* $\quad$ Mestre em Desenvolvimento Urbano pela Universidade Federal de Pernambuco (UFPE). Professora adjunta do Departamento de Arquitetura e Urbanismo, membro do Laboratório da Paisagem (UFPE), responsável pelo grupo de pesquisa do Núcleo de Estudos sobre a Subjetividade na Arquitetura (Nusarq). PhD em Sociologia da Cultura pela Université Paris Descartes/Sorbonne. Pesquisadora do Centre d'Études sur l'Actuel et le Quotidien (CEAQ/Sorbonne). Centro de Artes e Comunicação da UFPE - Laboratório da Paisagem. Avenida Professor Moraes Rego, 1.235, 50670-901, Cidade Universitária, Recife, PE, Brasil.

julietaleite@gmail.com

** Aluna do curso de Arquitetura e Urbanismo da Universidade Federal de Pernambuco (UFPE). Bolsista do Programa Institucional de Bolsas de Iniciação Científica do Conselho Nacional de Desenvolvimento Científico e Tecnológico (PIBIC/CNPq) entre 2014 e 2015. Centro de Artes e Comunicação da UFPE - Laboratório da Paisagem. Avenida Professor Moraes Rego, 1.235, 50670-901, Cidade Universitária, Recife, PE, Brasil.

rafaela.rasouza@gmail.com
} 
of landscapes in which where produced by them. As such, we have aimed toward the students to develop their critical thinking about the landscape in which they have been interacting. Finally the incorporation of the students into the architecture practice, therefore reveals to be a promising practice for the Architecture, the Urbanism, and the Landscaping Learning.

Keywords: Education. Architecture and Urbanism. Landscape theory. Logbooks.

\section{INTRODUÇÃO}

Este artigo refere-se a uma experiência pedagógica realizada entre 2012 e 2014 no curso de Arquitetura e Urbanismo da Universidade Federal de Pernambuco (UFPE), disciplina eletiva de Tópicos Especiais em Teoria III (TE Teoria III), cuja ementa trata do problema da paisagem na discussão teórica da arquitetura, do urbanismo e do paisagismo. Essa disciplina foi criada e faz parte do novo Projeto Pedagógico do Curso de Arquitetura e Urbanismo em vigor desde 2010 (PPC2010). Entre as propostas do PPC2010, está a articulação das disciplinas de um mesmo período a partir da integração de conteúdos na disciplina Projeto de Arquitetura, Urbanismo e Paisagismo. O PPC2010 buscou reforçar a indissociabilidade das disciplinas teóricas e práticas no aporte de conceitos e métodos, o que ajuda os alunos a reconhecerem um mesmo objeto de estudo e intervenção. A disciplina TE Teoria III foi construída pela equipe de professores do Laboratório da Paisagem e tem sido ministrada pela professora Julieta Leite. Com carga horária de 15 horas, destina-se aos alunos a partir do terceiro período do curso e tem como objetivo construir um olhar crítico sobre o pensar e fazer paisagem.

A construção e a realização dessa experiência será apresentada em três momentos. $\bigcirc$ primeiro trata da construção da disciplina e apresenta a base conceitual escolhida para a introdução de noções teóricas sobre paisagem aos alunos do curso de Arquitetura e Urbanismo. Em seguida, será apresentada a execução do plano de curso da disciplina, os principais conteúdos discutidos e a elaboração do exercício dos Cadernos de Bordo, que consistiu na produção individual de um caderno no qual os alunos precisaram responder questões levantadas em sala de aula em forma de textos e registros de paisagens. Por fim, este artigo apresentará os resultados dessa experiência didática, registrada nos Cadernos de Bordo. Trata-se de um exercício criativo e de aproximação com o objeto estudado, uma vez que se articula a paisagens vivenciadas pelos alunos (figuras 1 e 2). $\bigcirc$ Caderno de Bordo consiste numa experiência metodológica de ensino e no reflexo dos resultados da disciplina, sendo, portanto, o objeto de análise e discussão deste artigo.

"A paisagem é algo mais do que o que se vê, é a captação do mundo tal como o percebemos na experiência vivida, envolve todos os sentidos e assim acaba envolvendo o observador. É uma das poucas artes que consegue tal fato." (Reprodução do texto da figura 2 da aluna Ana Ísis, 2014). 
Teoria da Paisagem em Cadernos de Bordo: Uma Experiência no Ensino de Arquitetura e Urbanismo
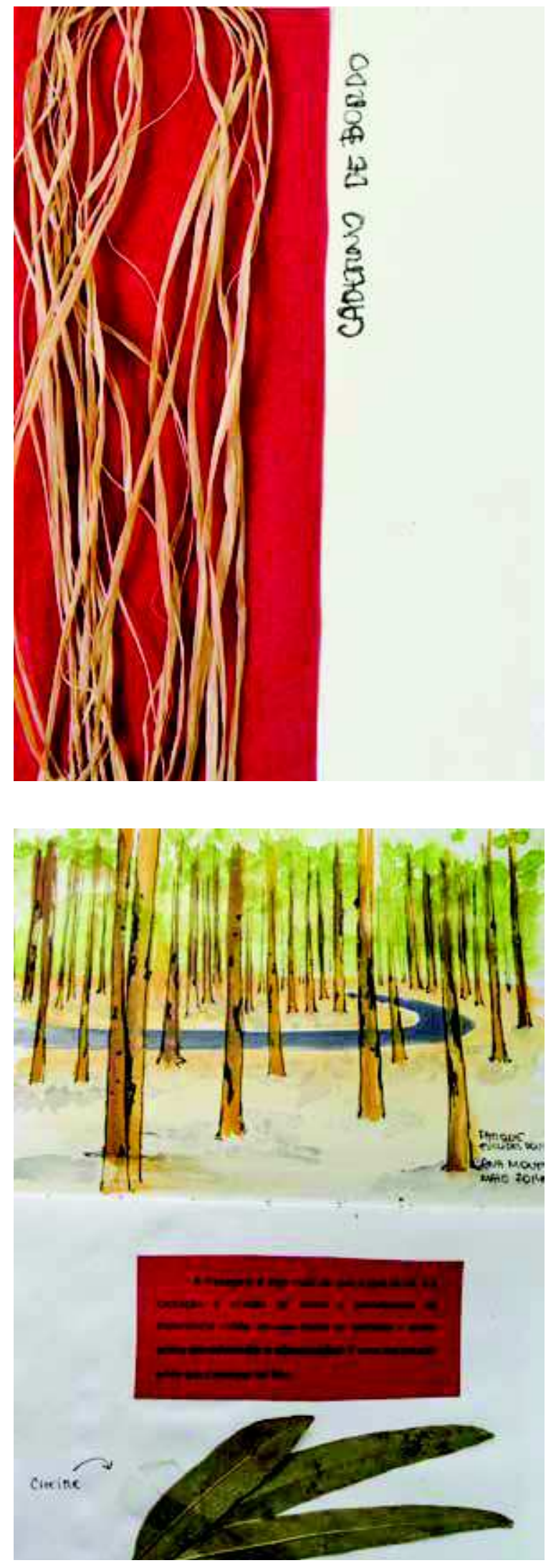

Figura 2 Interior do Caderno de Bordo da aluna Ana Ísis, 2014.
Figura 1 Capa do Caderno de Bordo da aluna Ana Ísis, 2014. 


\section{POR UMA NOÇÃO DE PAISAGEM}

O termo "paisagem" tornou-se popular nos últimos anos, difundindo-se com diferentes conotações no meio científico - como na filosofia e na história da arte - e nos discursos das práticas de planejamento urbano, das políticas de meio ambiente ou de turismo. As pessoas falam sobre paisagens naturais, paisagens culturais ou apenas paisagem. Mas o que está por trás dessa palavra? Em ¿̇Por qué hablar ahora de paisaje?, Rosa Barba (2000) discute tal questionamento:

A respeito da paisagem, há quase uma impossibilidade de defini-la hoje de maneira absoluta a partir de uma única perspectiva, visto a pluralidade das disciplinas que se aproximam dela, a estudam, a fazem sua e a querer dizer muitas coisas. (BARBA, 2000, p. 14, tradução do autor).

Diversos conceitos de paisagem surgem entre variados campos de conhecimento, de acordo com aspectos que thes são relevantes, como ecologia, geografia e arquitetura. Nos discursos sobre as questões urbanas contemporâneas, o termo paisagem tem sido associado à preocupação com a qualidade de vida e dos territórios habitados. Nesse panorama, uma nova abordagem da paisagem, em perspectivas teórica e prática, tem se mostrado necessária e em processo de construção. Como aponta Jean-Marc Besse (2014, p. 7-8): A paisagem constitui uma perspectiva nova para as questões ligadas ao projeto urbano e à concepção de cidade. [...] Hoje, já surgem novas perguntas a respeito da paisagem e, em particular, novas exigências teóricas e práticas são feitas a seu respeito.

Diante dessa variedade de acepções, identificamos a importância da construção de uma noção de paisagem para os estudantes de arquitetura e urbanismo tida não apenas como objeto da disciplina e da formação e atuação profissional, mas como algo com o qual interagem diariamente. Procurou-se, inicialmente, definir um viés epistemológico para estruturar os conteúdos abordados na disciplina. Decidiu-se trabalhar três "entradas" para a questão da paisagem: i) como construção cultural, intelectualizada, informada principalmente pela pintura e cuja imagem é coletivamente partilhada: a paisagem como uma invenção. (CAUQUELIN, 2000); ii) como experiência sensível vivida pelo sujeito, percebida através da globalidade dos sentidos por meio de abordagem fenomenológica: a paisagem como um estado de alma. (PARRET, 2005); iii) como direito associado à qualidade de um componente de um território, eminentemente urbano, necessário para garantia de habitabilidade. (MONTILLET, 2011). Salienta-se que essas "entradas" não são excludentes; ao contrário, complementam-se.

Uma vez definida essa postura teórica, o desafio foi elaborar um modo de construir tais noções com os alunos de maneira clara e pertinente. Não cabe, aqui, discorrer sobre os argumentos acerca dessas três "entradas" ou problemáticas paisagísticas. $\bigcirc$ objetivo é apresentar a construção do método de ensino e os resultados obtidos na disciplina. Cabe, no entanto, colocar como foi apresentada aos alunos parte dos conteúdos teóricos. 
As "entradas" escolhidas para a introdução de noções teóricas sobre paisagem foram trabalhadas com os alunos em aulas guiadas por um texto base. O texto escolhido foi "We are the landscape: understanding the European Landscape Convention", de Cecilia Berengo e Sara Di Maio (2008), elaborado para divulgação da Convenção Europeia da Paisagem (CEP, 2000). Com linguagem simples e convidativa, permitiu trabalhar noções de paisagem que levaram os alunos a refletir sobre: a importância das paisagens, paisagens cotidianas e extraordinárias, a participação dos cidadãos enquanto atores e expectadores da paisagem.

Em sala de aula, os conteúdos do texto base foram explorados e desdobrados por meio de referências teóricas previamente selecionadas, bem como a partir de exemplos e ilustrações trazidas do cinema, das artes visuais e da literatura. Por exemplo, ao discutir o conceito de paisagem apresentado pela $\operatorname{CEP}(2010$, p. 25) - que a designa como "[...] uma parte do território, tal como é percebido pelas populações, cujo caráter resulta da ação e da interação de fatores naturais e ou humanos [...]" -, discutiu-se em que consiste a percepção por meio da leitura de autores como Lynch (1997) e Berque (2010). Em Território e pessoa, a identidade humana, Berque conta o episódio de quando retornou ao local onde viveu com seus pais durante a infância e, ao vislumbrar novamente as montanhas de Seksawa, disse: "[...] meu pai tornou-se paisagem". (BERQUE, 2010, p. 14). Por meio desse exemplo, discutiu-se como a paisagem é capaz de evocar lembranças e sensações ligadas a lugares concretos. A partir de uma vivência pessoal, o autor apresenta uma perspectiva filosófica a respeito da paisagem, que fundamenta uma noção conceitual e abre margem à ampla discussão na disciplina de formação em arquitetura e urbanismo.

Diferentes noções de paisagem foram apresentadas aos alunos a partir das formas de relação que os homens estabelecem com seus territórios, considerando a percepção, a cultura, os sentidos, a memória e um conjunto de elementos subjetivos e coletivos em contínua elaboração e transformação. Procurando trazer reflexões mais próximas ao fazer do arquiteto, salientou-se que as intervenções elaboradas em seus projetos podem ressaltar aspectos subjetivos que proporcionam ambientes ricos em experiências e sensações.

Ao final da disciplina discutiu-se sobre as ações de conservar, projetar e gerir paisagens no contexto contemporâneo. Explorou-se a ideia da "[...] demanda por um direito à qualidade da paisagem do qual todos podem desfrutar à vontade" (MONTILLET, 2011 , p. 10) - num momento em que a cidade corre o risco de se tornar cada vez mais inabitável e sem atrativos - e a ideia da necessidade de englobar igualmente outros aspectos, pelos quais a natureza, a sociedade, a estética, o patrimônio e a economia caminham em paralelo. A partir desses procedimentos e temáticas, construiu-se o embasamento teórico sobre paisagem. A apreensão e os desdobramentos dessas noções foram registrados pelos alunos no exercício dos Cadernos de Bordo, por meio do qual se buscaram aproximações e reconhecimentos das paisagens vivenciadas por eles.

\section{PASSO A PASSO}

Com carga horária de 15 horas, a disciplina de TE Teoria III foi distribuída em seis unidades programáticas, que ocorreram uma vez por semana, no formato de aulas 
expositivas e momentos de discussão. Este artigo reporta-se a uma amostra de cinquenta cadernos, que representam a produção de três turmas entre 2012 e 2014.

Como já colocado, tomou-se como guia o texto de Berengo e Di Maio (2008), "We are the landscape...", cujos temas foram aprofundados por meio de outros textos, previamente selecionados. Na aula 2, por exemplo, sobre "como percebemos a paisagem", foram trabalhados trechos literários de duas obras de Ítalo Calvino: As cidades invisíveis (2010) e Marcovaldo: ou as estações na cidade (1994). Por meio das histórias e personagens de Calvino, exploraram-se as descrições de paisagens, suas experiências e o imaginário construído em torno delas.

Em cada aula expositiva, desenvolveu-se um tema de introdução à teoria da paisagem. Ao final de cada aula, apresentava-se uma questão a ser respondida extraclasse, com o objetivo de levar o aluno a refletir sobre os conteúdos trabalhados (tabela 1).

Tabela 1 Temas Abordados e Questões Colocadas para Elaboração dos Exercícios a Cada Aula

\begin{tabular}{|c|c|c|}
\hline \multicolumn{3}{|c|}{ Unidades Programáticas } \\
\hline Aula & Tema & $\begin{array}{l}\text { Tema para exercício do Caderno de } \\
\text { Bordo }\end{array}$ \\
\hline 1 & $\bigcirc$ que é paisagem? & Livre registro de paisagens. \\
\hline 2 & Como percebemos a paisagem? & $\begin{array}{l}\text { Questão de enquadramento ou de } \\
\text { sentimento? }\end{array}$ \\
\hline 3 & Por que a paisagem é importante? & $\begin{array}{l}\text { Somos atores ou espectadores da } \\
\text { paisagem? }\end{array}$ \\
\hline 4 & $\begin{array}{l}\text { O que garante a qualidade de uma } \\
\text { paisagem? }\end{array}$ & Por que a paisagem é importante? \\
\hline 5 & Paisagem in situ: o bairro da Várzea & $\begin{array}{l}\text { Que traços a caracterizam como } \\
\text { paisagem recifense? }\end{array}$ \\
\hline 6 & \multicolumn{2}{|c|}{$\begin{array}{l}\text { Fechamento da disciplina: } \\
\text { entrega dos Cadernos de Bordo e discussão sobre os exercícios. }\end{array}$} \\
\hline
\end{tabular}

Fonte: Julieta Leite e Rafaela Souza, 2015.

Na primeira aula, foi colocada a pergunta "o que é paisagem?", com o objetivo de levantar diversas definições de paisagem trazidas pelos alunos. Procurou-se levá-los a refletir sobre a importância e a dificuldade da definição do objeto e sensibilizar olhares em relação à paisagem ao redor.

A segunda aula se desenvolveu em torno da questão "como percebemos a paisagem?", bastante pertinente para a construção de um entendimento da paisagem relacionada à questão levantada na primeira aula. Com apoio de textos de Yifu-Tuan (1983), Calvino (1994; 2010) e do texto de Berengo e Di Maio (2008), "We are the landscape...", procurou-se compreender a paisagem a partir de seu componente sensível. 
A terceira aula lançou aos alunos a pergunta "por que a paisagem é importante?", tendo como objetivo convidá-los a pensar sobre os valores da paisagem e as formas como atuamos sobre a mesma. Nessa aula a paisagem foi apresentada como componente essencial do ambiente humano e como construção coletiva, tomando como referência teórica o texto "A imagem da cidade", de Kevin Lynch (1997).

Na quarta aula levantou-se a questão sobre "o que garante a qualidade de uma paisagem?". Desenvolveu-se uma visão de paisagem enquanto bem coletivo associado à qualidade de vida. Nessa aula estimulou-se a construção de um olhar mais crítico do aluno a partir de exemplos próximos à sua realidade.

A quinta aula aconteceu em contato direto com uma paisagem. Por meio de uma visita de campo, pôde-se retomar conceitos trabalhados em sala de aula numa experiência prática. A questão indicada para a realização do exercício do Caderno de Bordo procurou explorar o olhar do aluno para visões de paisagem que fossem além dos aspectos morfológicos, incorporando fatores histórico-culturais, sentimentais, numa ideia de paisagem enquanto transmissora de traços identitários (figuras 3 e 4). A sexta e última aula destinou-se à entrega e apresentação dos Cadernos de Bordo, com uma discussão coletiva sobre os resultados da disciplina.

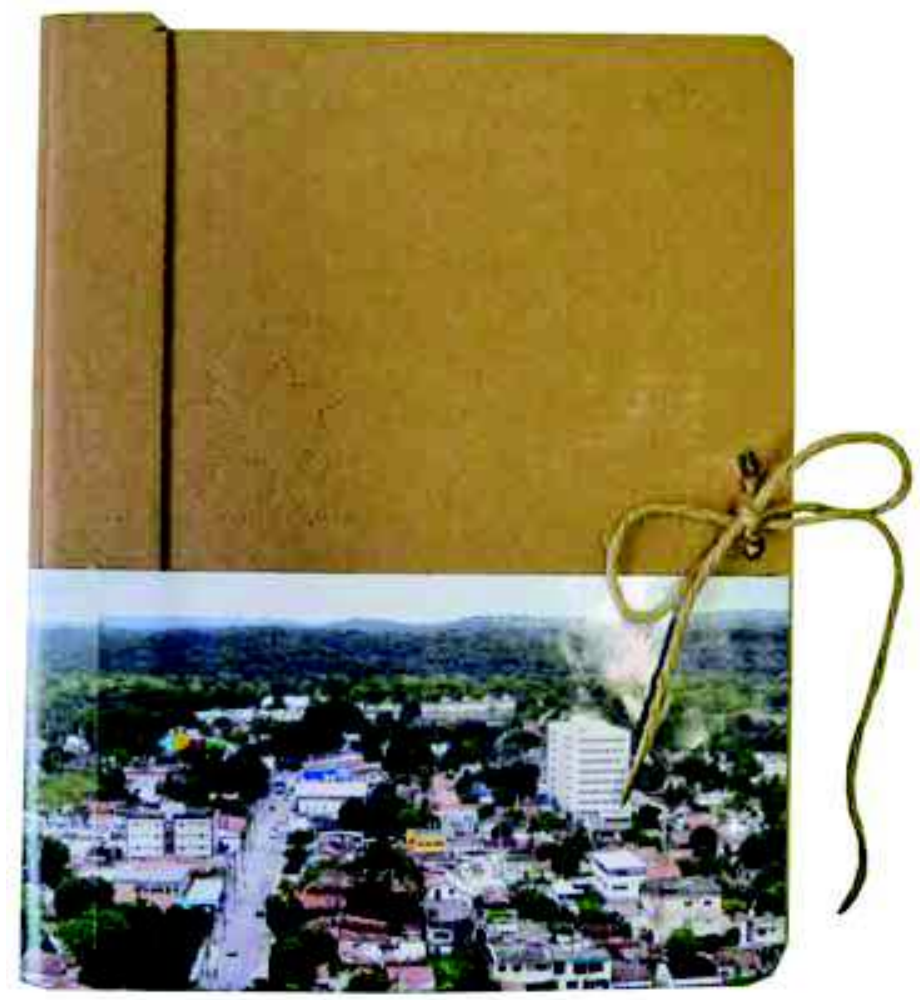

Figura 3 Capa do Caderno de Bordo do aluno Juan David, 2013. 


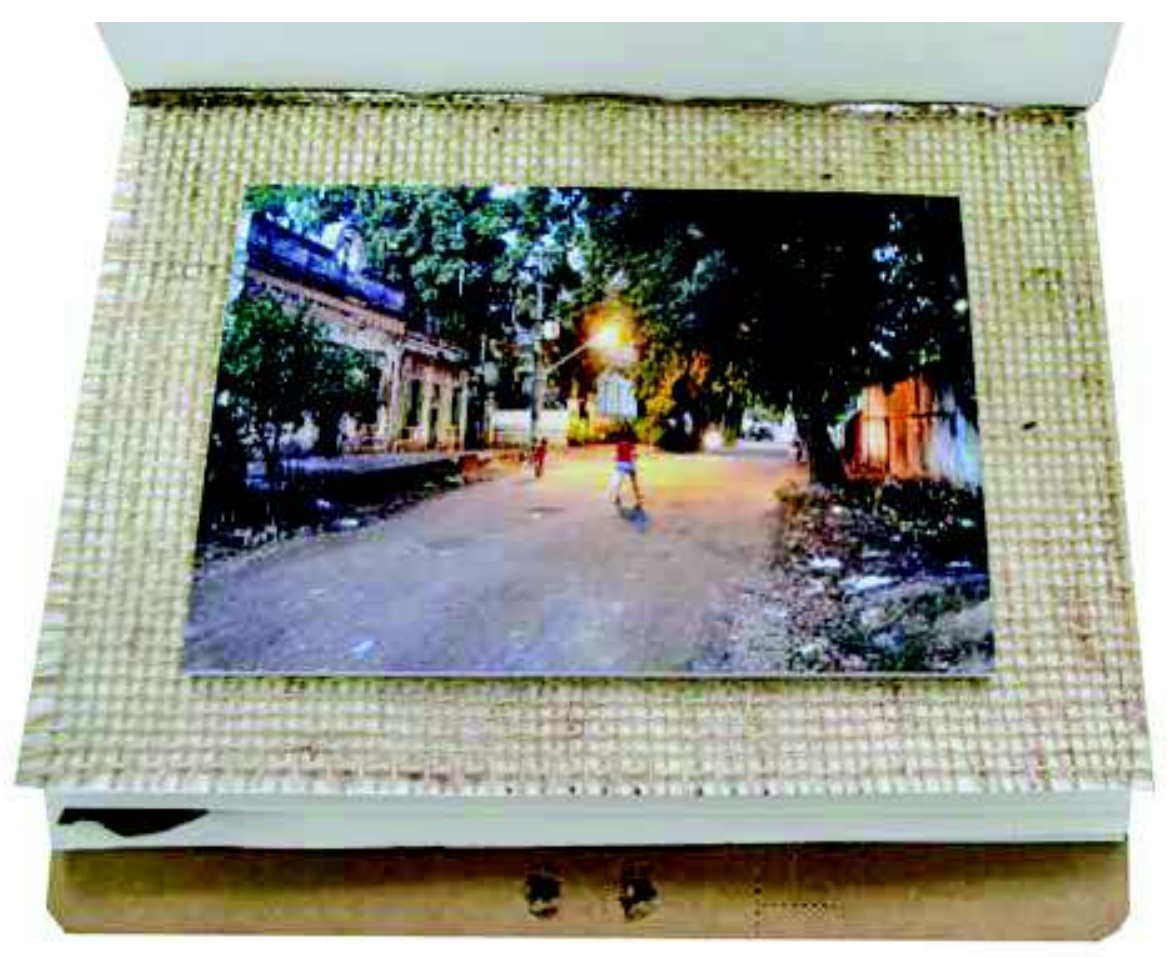

Figura 4 Interior do Caderno de Bordo do aluno Juan David, 2013.

"Do espírito bucólico, rural e aconchegante, do bairro nos limites da 'cidade'. Assim é a Várzea de engenhos e verde." (Reprodução do texto do aluno Juan David, 2013).

\section{REGISTROS NOS CADERNOS DE BORDO}

Apesar do caráter teórico da disciplina - desenvolvido a partir de aulas expositivas, leituras de textos e discussões -, o exercício teve cunho mais prático. Tomou a forma de um Caderno de Bordo em que as respostas às questões colocadas ao final das aulas deveriam ser apresentadas como texto e imagem de uma paisagem escolhida pelo aluno, com a qual interagiu. Mais do que ilustrar os cadernos, as imagens participaram da construção das respostas para cada questão. Nas duas primeiras experiências da disciplina, os alunos registraram a paisagem em fotografia. Nos períodos seguintes, passou a ser solicitado o registro feito em desenho, levando-os a exercitar essa forma de expressão e a dedicar mais tempo ao exercício de observação e comunicação da paisagem. Por meio desse exercício, os alunos foram levados a retomar as noções teóricas e conceituais levantadas em classe num contexto de contato direto com a paisagem, questionando e refletindo sobre a mesma.

Embora tenha sido colocada a pergunta "o que é paisagem?" logo no primeiro dia da disciplina, o tema do exercício do caderno foi livre. Observou-se, nos primeiros registros, clichês ou ideias comuns sobre paisagem. As imagens representadas reportavam-se, em sua maioria, a paisagens urbanas, podendo ser classificadas em dois grupos principais: 
Teoria da Paisagem em Cadernos de Bordo: Uma Experiência no Ensino de Arquitetura e Urbanismo

o primeiro, com referência a imagens de cartões-postais (figura 5); o segundo, com cenários do cotidiano (figura 6). Tanto num grupo como no outro, as imagens faziam parte de paisagens com as quais os alunos interagiam.

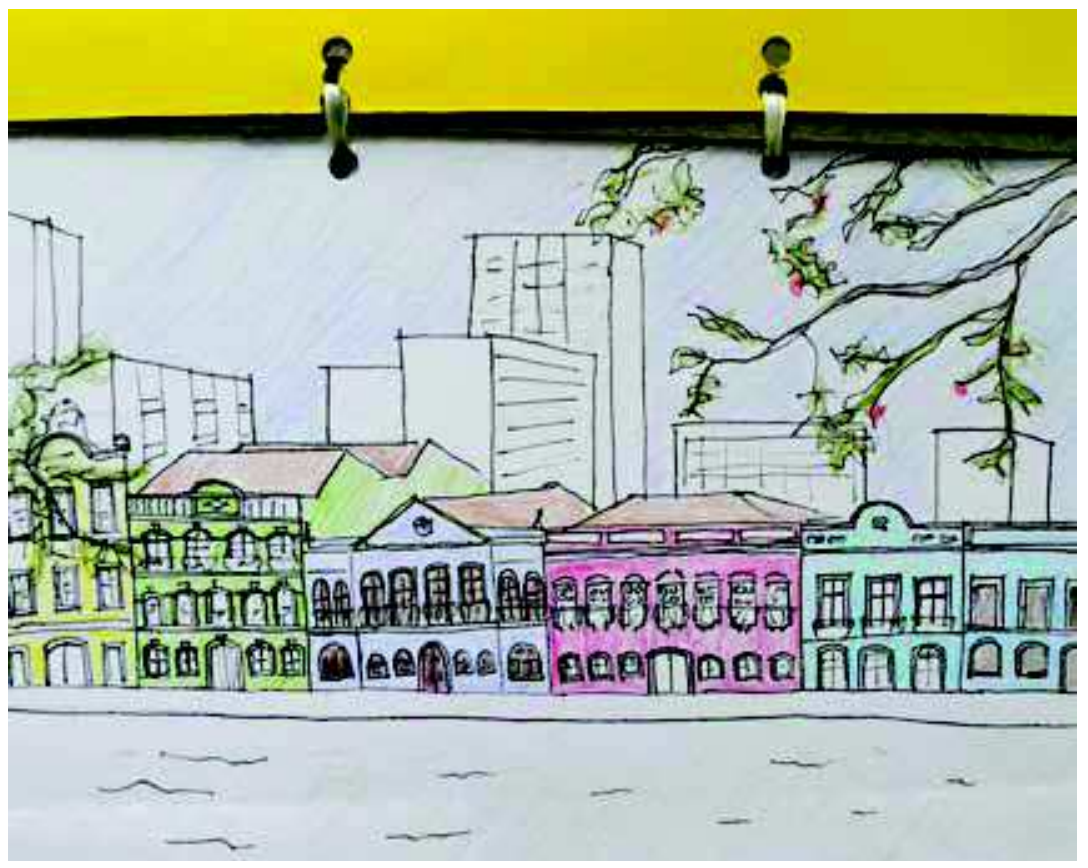

Figura 5 Registro do exercício 1 da aluna Laryssa Araújo, 2014.

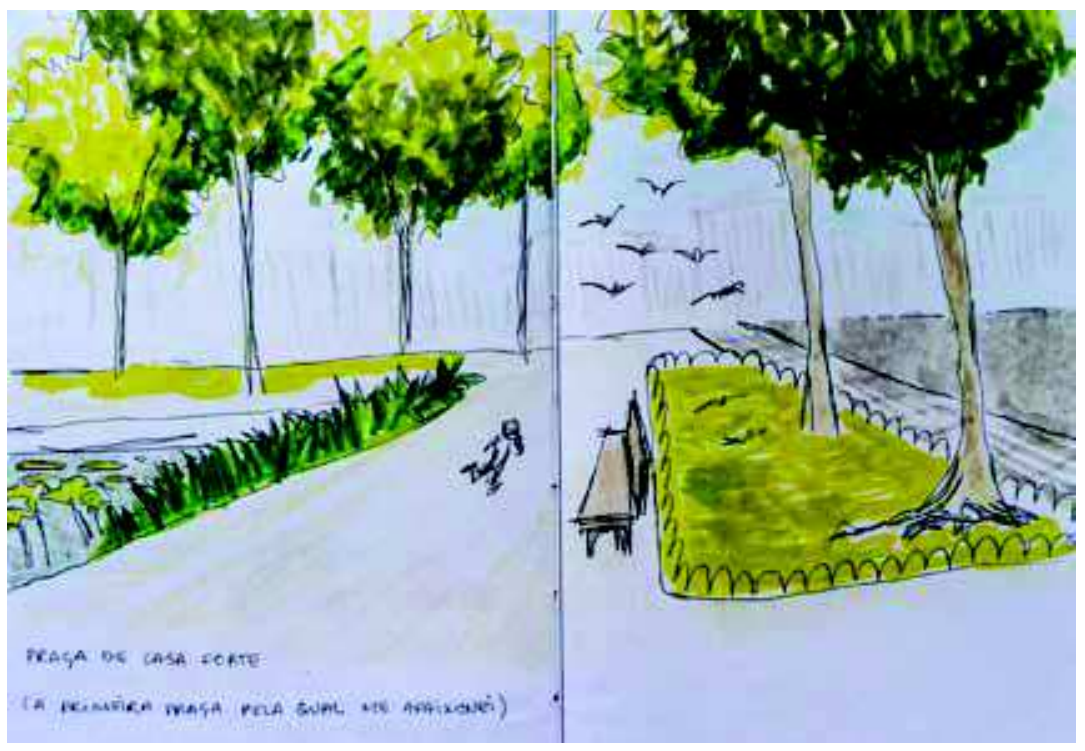

Figura 6 Registro do exercício 1 da aluna Marília Chaves, 2014.

Nos textos que se referem às imagens apresentadas no primeiro grupo, das "imagens de cartões-postais", o conteúdo expressou a preocupaçãodo dos alunos em descrever o conteúdo da foto, mais do que buscar uma definição de paisagem. A exemplo das palavras da aluna Thaís Chmelar (2012): 
"Eu poderia me concentrar a falar da existência de apenas uma dessas paisagens, mas é inevitável não se deixar envolver por todas elas. E isso prova a complexidade de se experienciar e descrever uma paisagem, pois uma máquina não consegue registrar a extensão e a qualidade do que vemos. E as palavras se tornam insuficientes para se descrever tantas sensações."

Já no segundo grupo de imagens, que se reportou a "cenários do cotidiano", as descrições apresentaram conteúdos bastante relacionados aos sentidos e à experiência pessoal, como se observa nas palavras do aluno Talys Medeiros (2014):

"Retratei a vista do pôr-do-sol enquadrada pelo pano de cobogós da escada da minha casa. Através desse enquadramento eu podia admirar o momento que, para mim, é o mais belo do dia, tendo como cenário a cidade onde vivo, Moreno, com suas colinas tão características e marcantes."

De forma muito expressiva, esse momento foi o mais rico em referências literárias, poéticas, musicais e cinematográficas, o que demonstrou a necessidade de recorrer a recursos metafóricos para descrição e representação de paisagens, muitas vezes, "interiores".

"Nada mais chato que nos quererem mostrar uma paisagem. Quando compreenderão que a gente as vê sem saber? É como se fossem elas que estivessem olhando para nós." (Mário Quintana, citado pela aluna Lara Moura).

Nesse primeiro exercício, as paisagens apresentadas foram, em geral, associadas a noções de pertencimento, de relação com os lugares vivenciados, deixando claro que o componente subjetivo da paisagem é fundamental para sua apreensão. Por outro lado, apesar de alguns alunos terem comentado sobre figuras humanas nas descrições de paisagens, poucos cadernos representaram imagens de pessoas.

O segundo exercício questionou se a paisagem é "uma questão de enquadramento ou de sentimento", levando os alunos a discutirem sobre como se percebe a paisagem. Observou-se, na maioria das respostas, que entenderam o questionamento como duas noções que se complementavam: "Enquadramento está impregnado de sentimento, e nenhuma percepção de paisagem é capaz de esgotá-la por inteiro. Há infinitas formas de percebê-la." (Marília Chaves).

Pôde-se notar que a ideia de enquadramento colocada pelos alunos estava, na maioria das vezes, associada a sentimentos expressos em emoções, memória de lugares e situações vividas. Alguns colocaram que fatores de ordem subjetiva moldaram suas percepções da paisagem, influenciando na escolha de um ângulo de visão, como nas palavras da aluna Maria Eduarda Pimentel (2014):

"Com certeza aquela rua, aquela casa, aquela calçada são a minha história e hoje ao representar esse lugar por meio de um desenho, fica claro a escolha dessa vista. Eu poderia ter escolhido qualquer visão da rua da Matriz e seus belos casarões, mas meus sentimentos, minha história, minha memória fizeram a escolha por mim." 
Teoria da Paisagem em Cadernos de Bordo: Uma Experiência no Ensino de Arquitetura e Urbanismo

Com esse exercício, os alunos entenderam que o enquadramento (o visível) e o sentimento (o invisível) das paisagens são carregados de informações intimamente associadas. Constataram que, mesmo mantido um mesmo enquadramento, o conteúdo ou informações das paisagens são muito dinâmicos. Nesses casos, o enquadramento foi descrito como um quadro de referência que permitiu aos alunos acompanhar a transformação da paisagem em diversas situações: ao longo das estações do ano, da ação humana, das mudanças em seu estado de humor. Tal constatação foi motivo para alguns recorrerem a representações sucessivas da paisagem segundo um mesmo enquadramento (figuras 7 e 8 ).

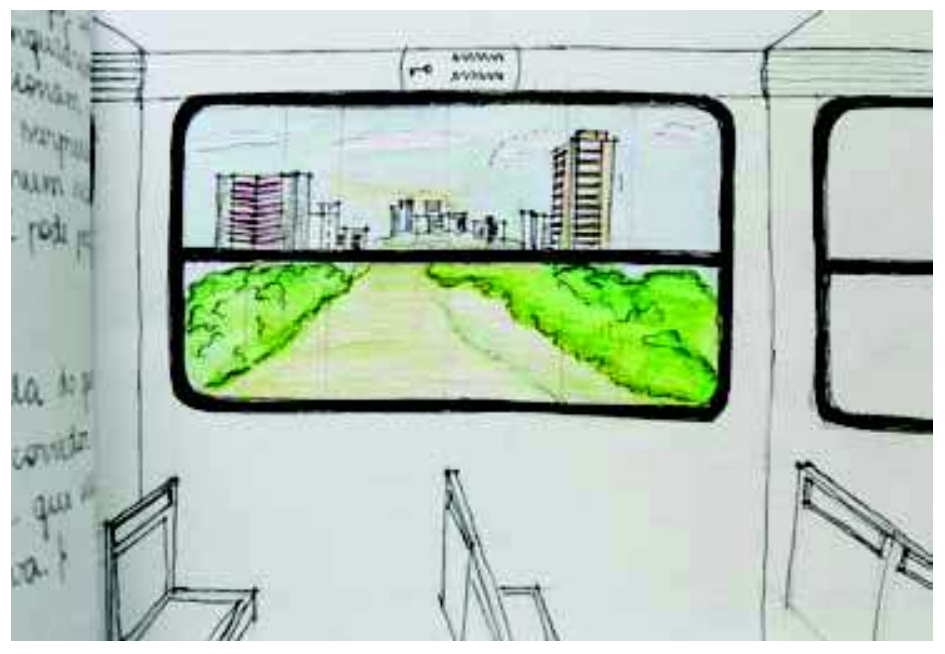

Figura 7 Registro do exercício 2 da aluna Marília Lucena, 2014.

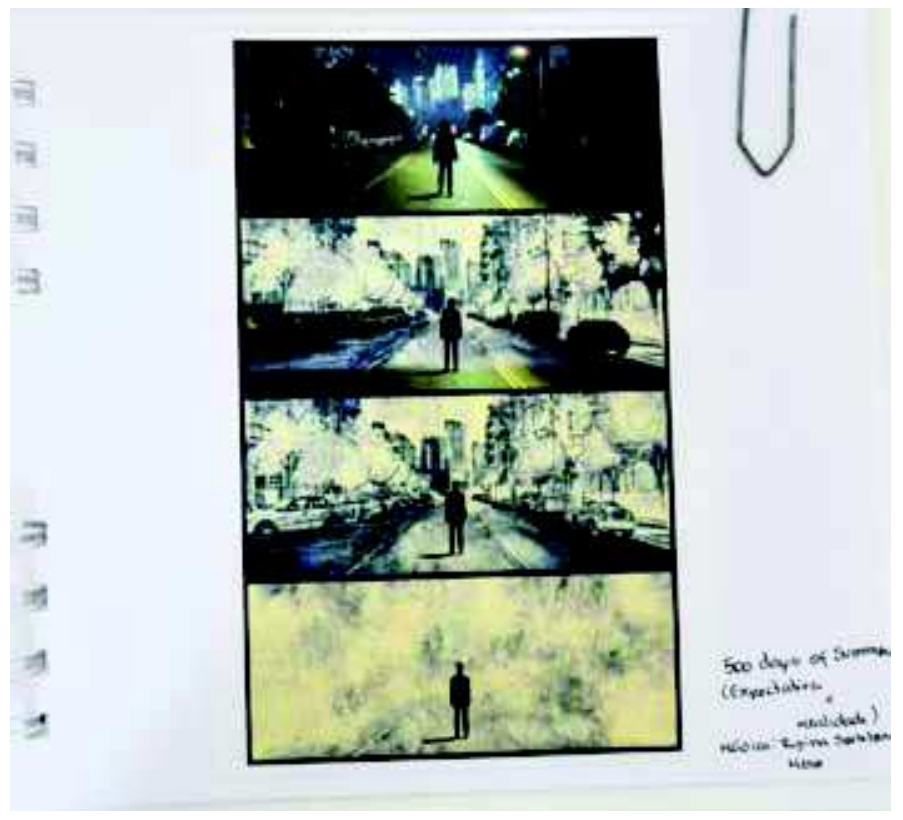

Figura 8 Registro do exercício 2 da aluna Jéssica Roosen, 2012. 
O tema do terceiro exercício reportou-se à importância das paisagens. A questão levantada fez referência ao papel dos cidadãos: "somos atores ou espectadores?". Tal indagação levou os alunos a refletirem sobre suas relações com a paisagem - não só como observadores, mas como agentes em seu processo de formação e transformação. Nesse exercício a ação do homem sobre o território passou a ser incorporada às reflexões sobre as paisagens, fossem excepcionais ou cotidianas. As imagens dos cadernos passaram a representar maior número de figuras humanas (figuras 9 e 10).

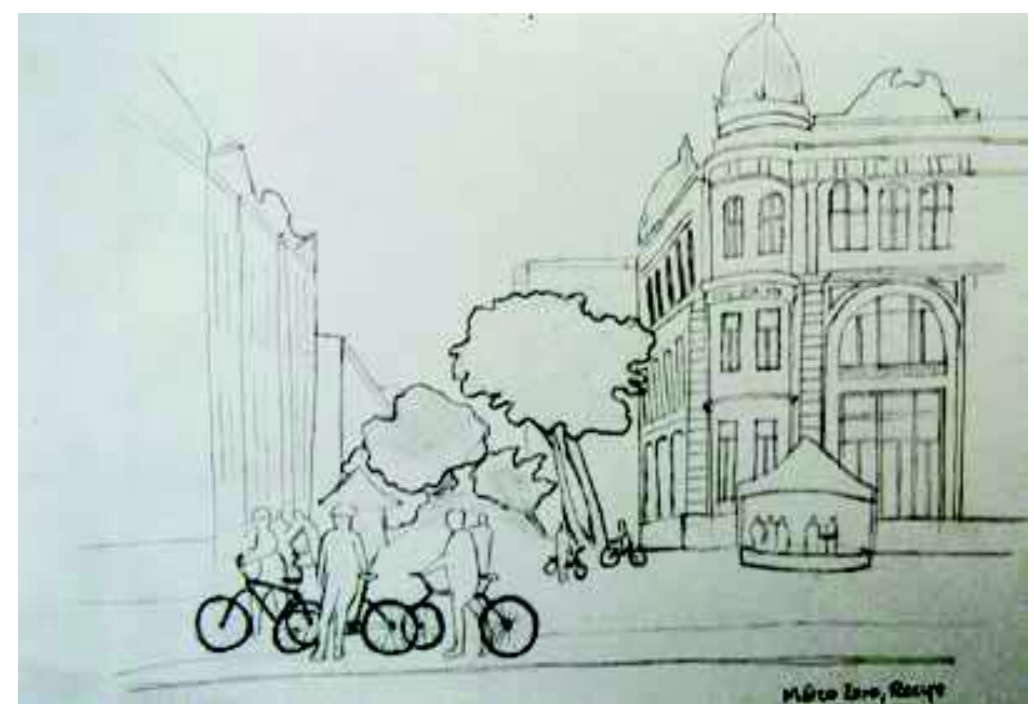

Figura 9 Registro do exercício 3 da aluna Ingrid Lopes, 2014.

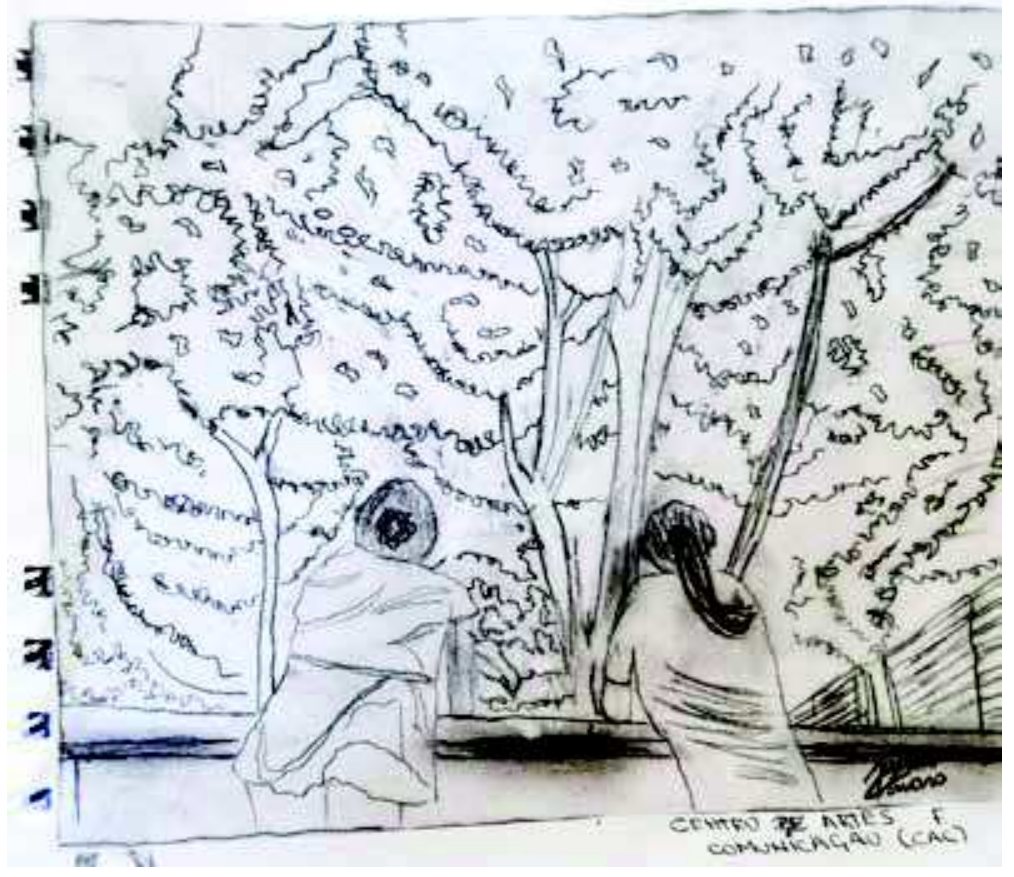

Figura 10 Registro do exercício 3 da aluna Juliane Bezerra, 2012. 
Em relação aos conteúdos das imagens, observou-se novamente, na maioria dos cadernos, a escolha por representar lugares emblemáticos, como imagens de cartões-postais, vistas, panoramas sobre rios, pontes e casarios que marcam a imagem da cidade onde vivem. Os alunos interpretaram esses elementos como parte de paisagens coletivamente partilhadas, da qual o homem é ora espectador, ora ator. Nas palavras do aluno Thalys Medeiros (2014):

"A construção de uma paisagem não ocorre exclusivamente por conta dos elementos naturais, mas também pelas intervenções que realizamos no território, por mais simples e cotidianas que algumas delas possam parecer."

Alguns alunos reforçaram a importância das paisagens enquanto bens e produtos coletivos, noção próxima à de patrimônio, expressa nos termos aplicados à paisagem como "reflexo", "espelho de quem a habita", "código genético de uma região", "traço de uma história". Em outro grupo de cadernos, observou-se entendimentos da paisagem por meio de relações mais íntimas e individuais, expressas nas palavras "ser paisagem", "paisagem conquista", "a paisagem existe em nós":

"Tem a paisagem essa força de dizer quem somos, de nos inserir como parte dela e trazer sentidos às experiências vivenciadas." (Rafaela Souza).

"Essa paisagem faz parte de mim. É profundamente bela porque a vivi. Eu sinto na alma seus significados." (Marília Chaves).

Tais noções de paisagem - como elemento de identificação coletiva ou individual levaram os alunos a perceberem sua importância por intermédio de valores históricos, rememorativos, ecológicos, educativos e literários; a paisagem como bem comum e transmissora de significados. Nas respostas a esse exercício, começaram a esboçar olhares mais críticos. Questionaram, por exemplo, a qualidade das paisagens de suas cidades e as transformações pelas quais vêm passando.

O quarto exercício teve caráter peculiar, trazendo para sala de aula o debate em torno da proposta de uso e ocupação do terreno do cais José Estelita, no bairro de São José, sítio histórico na cidade de Recife. Esse projeto propõe, para a frente de água da cidade, a construção de edifícios com mais de quarenta pavimentos, com usos que vão de residencial a hoteleiro e centros comerciais. Tal proposta repercutiu num forte movimento da sociedade civil em oposição à construção do empreendimento, tendo como um dos pontos centrais de argumentação o "direito à cidade" e a "proteção da paisagem cultural". A partir desse exemplo, os alunos passaram a pensar sobre formas de atuar sobre a paisagem, trazendo em seus cadernos questões sobre como garantir a qualidade das paisagens enquanto direito e dever de todos. À luz de conceitos e ideias vistos em sala de aula, exploraram-se as noções de vivência e apropriação como formas de apreensão e, consequentemente, de valoração e conservação das paisagens: 
"Temos que ser capazes de reconhecer a paisagem para continuar a atribuir valor [...] O que garante a qualidade da perpetuação das características é o nosso cuidado com a preservação da paisagem. E preservar não é impedir mudanças: é garantir que as transformações respeitem o contexto existente e não alterem a essência dos lugares." (Marília Chaves).

Devido ao tema, desenhos, questionamentos e referências apresentados nos cadernos trabalharam de forma mais significativa a conservação e preservação da paisagem como forma de manutenção de estruturas que contam histórias das cidades. A maioria das imagens apresentadas pelos alunos representava o cais José Estelita (figura 11).

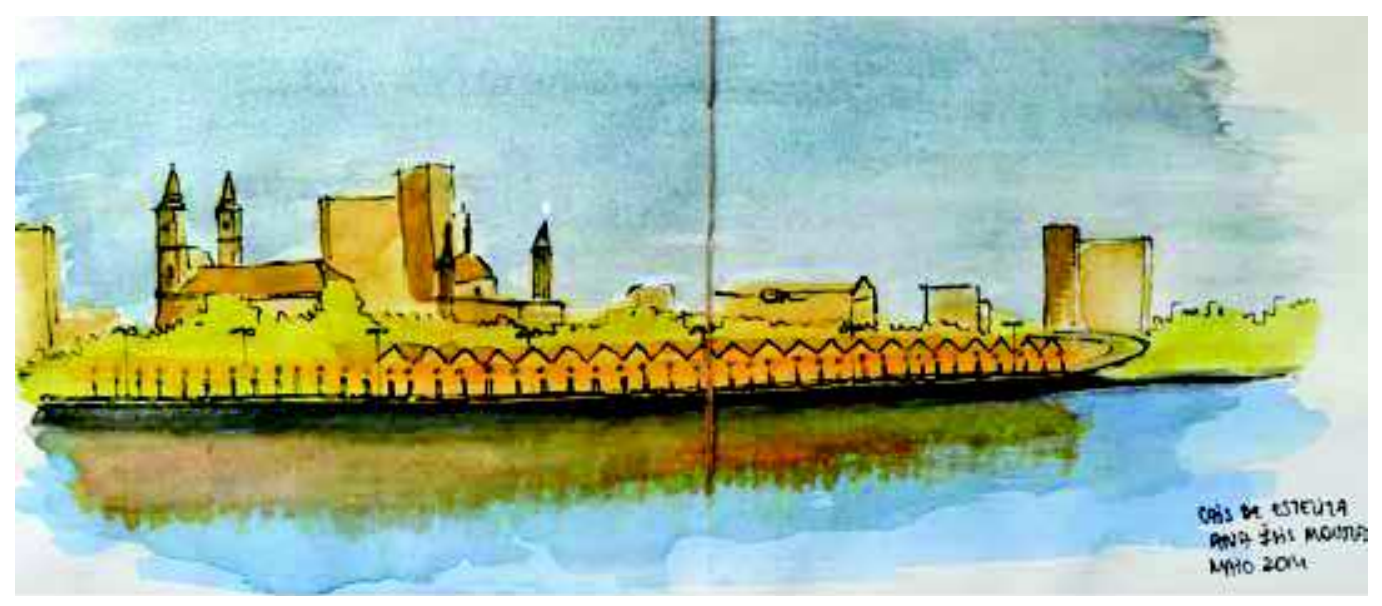

Figura 11 Registro do exercício 4 da aluna Ana Ísis, 2014.

Interpretada como "reflexo de nós", a paisagem foi apresentada nos comentários dos alunos como direito que precisa ser garantido hoje e numa perspectiva futura, por tratar-se de um bem cujos valores não devem ser reconhecidos por poucos indivíduos ou grupos sociais, pois têm força coletiva. Essas questões chamam atenção para tomadas de decisão do poder público em relação às paisagens excepcionais e às cotidianas.

"A existência de uma paisagem depende das influências do nosso olhar, da nossa sensibilidade e da nossa cultura em relação a uma realidade espacial. Por isso ela é o reflexo de nós mesmos (como sociedade), seja do que somos ou do que já fomos." (Talys Medeiros).

A quinta aula aconteceu numa visita ao bairro da Várzea, onde há presença considerável de espaços livres e naturais, localizado próximo à universidade (figura 8). O último exercício teve a intenção de levar os alunos a verem e sentirem uma paisagem, interrogando-os se carregava traços identitários da cidade e de seus cidadãos.

"O bairro ainda é predominantemente horizontal. Mesmo a partir de certa distância pode-se observar a torre de sua igreja matriz (do século XVI) ou a fileira de palmeiras 
que acompanha a praça delimitando seu espaço justamente com a abundante massa arbórea, que é um dos aspectos marcantes do bairro."

Em outros casos, observou-se nos alunos sensações de surpresa ao descobrirem um lugar na cidade ou reverem, de outra forma, uma paisagem que fez parte do seu cotidiano, mas apreendida apenas "de passagem". É o que coloca a aluna Maysa Aquino:

"Ao caminhar pelo bairro da Várzea com olhar mais crítico na percepção da paisagem ofereceram-se outras possibilidades de descobertas e vivências. Acostumada com o fluxo intenso de uma de suas avenidas principais - e limitada a observar o entorno sempre com pressa - nunca tinha me detido nos vários detalhes contidos na paisagem desse território."

O último dia de aula foi destinado à apresentação e entrega dos Cadernos de Bordo. Tidos como objetos bastante íntimos, a apresentação dos cadernos iniciou-se de forma tímida, mas logo deu espaço a ricos debates sobre as paisagens escolhidas e seus conteúdos. Cada aluno apresentou um exercício, e, em seguida, abriram-se discussões. Por fim, os cadernos circularam em sala de aula para que os alunos pudessem ver os dos colegas e, assim, alimentar outros debates. No momento da apresentação oral, os alunos tocaram em aspectos bastante pessoais sobre as paisagens representadas nos exercícios, continuando a fazer referência aos textos e exemplos trabalhados em sala de aula.

\section{CONSIDERAÇÕES FINAIS}

O objetivo da disciplina foi introduzir ao aluno do curso de Arquitetura e Urbanismo noções teóricas sobre a paisagem e despertar um olhar sensível e crítico sobre o território. Apesar de sua curta duração, as posições teóricas trabalhadas em sala de aula procuraram estabelecer um quadro de reflexões e ações possíveis ao fazer paisagístico.

Enquanto postura teórica, relacionada a uma perspectiva contemporânea, optou-se por explorar conceitualmente um entendimento da paisagem que perpassa a história da arte e aponta para valores coletivos, quadros simbólicos, horizontes éticos e políticos que fazem parte desse conjunto complexo e diversificado de preocupações com as transformações territoriais.

O exercício do Caderno de Bordo permitiu registrar os resultados das noções teóricas apresentadas em sala de aula - por vezes como provocação para o reconhecimento de valores e significados das paisagens, sobretudo daquelas vivenciadas pelos alunos.

Como então descrever, como dizer e representar esse espaço da paisagem que nos envolve e nos transpassa, que nos desola e nos transborda? Como falar da paisagem [...] e, mais exatamente como fazê-la, ou melhor, deixá-la falar? (BESSE, 2014, p. 52). 
Tais questionamentos de Besse, provavelmente, ficam ainda latentes para os alunos ao final da disciplina. No entanto, com a ajuda do texto base do autor, "We are the landscape...", pôde-se trabalhar definições consensuais e, sobretudo, reforçar o argumento de que a paisagem faz parte da vida das pessoas, de que nós somos a paisagem.

O exercício do Caderno de Bordo serviu não apenas para verificar a assimilação dos conteúdos apresentados, mas também para ajudar a revelar a riqueza de conexões construídas pelos alunos a partir das noções introdutórias da teoria da paisagem. A análise dos cadernos vem revelando novas referências - trazidas pelos alunos - para a interpretação da paisagem, na maioria das vezes vindas da poesia, do cinema e de outros teóricos. Sendo uma disciplina aberta a diferentes períodos, notou-se que os alunos já avançados no curso articulavam mais as noções da teoria da paisagem a conhecimentos de outras disciplinas, como a de Estética. Entre os alunos do início do curso, pôde-se observar que o conhecimento adquirido sobre a paisagem passou a contribuir com o desenvolvimento de seus projetos de arquitetura, urbanismo e paisagismo. Tais alunos apresentaram mais facilidade na análise da área de estudo e projeto, incorporando os valores da paisagem de forma mais pertinente, e indicaram uma preferência por trabalhar com temas ligados à paisagem em seus projetos.

\title{
REFERÊNCIAS BIBLIOGRÁFICAS
}

BARBA, Rosa. ¿̇Por qué hablar ahora de paisaje? In: AA.VV. Rehacer paisajes: arquitectura del paisaje en Europa. 1994-1999. Catalogo de la 1ª Bienal de Paisaje 1999. Barcelona: Fundación Caja de Arquitectos, 2000, p. 14-18.

BERENGO, Cecilia; DI MAIO, Sara. We are the landscape: understanding the European Landscape Convention. Florença: Giunti progetti educativi, 2009. 64 p.

BERQUE, Augustin. Território e pessoa, a identidade humana. Desigualdade \& Diversidade: Revista de Ciências Sociais da PUC-Rio, n. 6, jan./jul., 2010, p. 11-23.

BESSE, Jean-Marc. O gosto do mundo: exercícios de paisagem. Rio de Janeiro: EdUERJ, 2014. 234 p.

CALVINO, Ítalo. Marcovaldo: ou as estações na cidade. São Paulo: Companhia das Letras, 1994. 144 p.

As cidades invisíveis. São Paulo: Companhia das Letras, 2010. 152 p.

CAUQUELIN, Anne. A invenção da paisagem. São Paulo: Martins Fontes, 2007. 196 p.

FLORENÇA. Convenção Europeia da Paisagem (CEP), de 20 de outubro de 2000. Dispõe sobre as ações de proteção, gestão e planificação das paisagens europeias e organiza uma cooperação europeia acerca dos bens paisagísticos. Disponível em: <http://www.culturanorte.pt/fotos/editor2/2000-convencao_europeia_da_paisagemconselho_da_europa.pdf $>$.

LYNCH, Kevin. A imagem da cidade. São Paulo: Martins Fontes, 1997. 240 p.

MONTILLET, Philippe. Les trois âges du paysage. Projets de paysage, n. 6, set. 2011. Disponível em: <http://www. projetsdepaysage.fr/fr/les_trois_ages_du_paysage >. Acesso em: 16 mar. 2012.

PARRET, Herman. Le sentiment de paysage. In: Paysages \& valeurs: de la représentation à la simulation, Limoges, nov. 2005. Actes de colloques. Farid Boumédienne e Nicolas Couegnas (dir.). Disponível em: <http://epublications. unilim.fr/revues/as/3418>. Acesso em: 6 mar. 2012.

TUAN, Yi-Fu. Espaço e lugar: a perspectiva da experiência. São Paulo: Difel, 1983. 248 p.

\author{
Nota do editor \\ Submissão: 1 ago. 2015 \\ Aprovação: 30 nov. 2015
}

